\title{
Sleep Problems in Children with Autism Spectrum Disorder in Bangladesh: A Case-Control Study
}

\author{
Naznin Sultana ${ }^{1,2}$ \\ Md Asaduzzaman ${ }^{3}$ \\ Firoj al Mamun (D) ${ }^{1,4}$ \\ Ismail Hosen (D) ${ }^{1,4}$ \\ Qian $\mathrm{Yu}\left(\mathbb{D}^{5}\right.$ \\ Amir H Pakpour 6,7 \\ David Gozal (iD ${ }^{8}$ \\ Mohammed A Mamun (1D) 1,4 \\ 'CHINTA Research Bangladesh (Centre \\ for Health Innovation, Networking, \\ Training, Action and Research - \\ Bangladesh), Savar, Dhaka, Bangladesh; \\ ${ }^{2}$ Department of Public Health, North South \\ University, Dhaka, Bangladesh; \\ ${ }^{3}$ Department of Public Health, American \\ International University - Bangladesh, \\ Dhaka, Bangladesh; ${ }^{4}$ Department of Public \\ Health and Informatics, Jahangirnagar \\ University, Savar, Dhaka, Bangladesh; \\ ${ }^{5}$ Exercise Psychophysiology Laboratory, \\ Institute of KEEP Collaborative Innovation, \\ School of Psychology, Shenzhen University, \\ Shenzhen, 518060, People's Republic of \\ China; ${ }^{6}$ Social Determinants of Health \\ Research Center, Research Institute for \\ Prevention of Non-Communicable \\ Diseases, Qazvin University of Medical \\ Sciences, Qazvin, Iran; ${ }^{7}$ Department of \\ Nursing, School of Health and Welfare, \\ Jönköping University, Jönköping, Sweden; \\ ${ }^{8}$ Department of Child Health and the Child \\ Health Research Institute, The University \\ of Missouri School of Medicine, Columbia, \\ MO, USA
}

Correspondence: Qian Yu Exercise Psychophysiology Laboratory, Institute of KEEP Collaborative Innovation, School of Psychology, Shenzhen University, 5 I8060, People's Republic of China

Email yuqianmiss@163.com

Mohammed A Mamun

CHINTA Research Bangladesh, Savar,

Dhaka, I342, Bangladesh

Tel +880- I738592653

Email mamunphi46@gmail.com
Background: Sleep problems in children with Autism Spectrum Disorder (ASD) are highly prevalent, but little information is available on this issue in low- to middle-income countries (LMIC) such as Bangladesh. Therefore, the present study investigated the prevalence and socio-demographic determinants of ASD sleep disturbances in a comparison with typically developing children (TDC).

Methods: A cross-sectional interview study was carried out within a total of 446 Bangladeshi mothers, whose children's mean age was 8.1 \pm 2.9 years (151 ASD [8.5 \pm 2.7 years] and 295 TDC [7.9 2.9 years]); in addition to socio-demographics, the Child Sleep Habit Questionnaire (CSHQ) was used, and a cut-off score of 41 out of 93 points considered as reflecting sleep problems.

Results: About $89.7 \%$ of the children reported having problems in sleep, with ASD reporting higher frequency vs TDC $\left(94.00 \%\right.$ vs $\left.87.50 \% ; \chi^{2}=4.678, p=0.031\right)$. The overall mean CSHQ score was $48.7 \pm 7.6$ in total sample, whereas ASD children reported higher scores compared to TDCs $(50.9 \pm 8.1$ vs $47.5 \pm 7.0, p<0.001)$. Similarly, subscales of CSHQ such as sleep duration $(4.23 \pm 1.56$ vs $3.90 \pm 1.31, p=0.017)$, sleep anxiety $(7.23 \pm 2.05$ vs 6.45 $\pm 1.92, p<0.001)$, night waking $(3.82 \pm 1.07$ vs $3.17 \pm 1.89, p<0.001)$, parasomnias $(8.86 \pm 2.06$ vs $7.85 \pm 2.27, p<0.001)$, and sleep disordered breathing $(4.02 \pm 2.92$ vs $3.43 \pm 2.07, p=0.014)$ were more problematic among ASD compared to TDC. Lastly, 28.5\% of ASD reported taking sleep-related medications vs $0.3 \%$ for TDC $(n=1)$.

Conclusion: Bangladeshi ASD children are highly likely to manifest sleep disturbances, which warrant urgent implementation of parental educational and support programs to mitigate the impact of sleep problems in ASD families.

Keywords: sleep problems, insomnia, ASD, autism spectrum disorder, child sleep habit questionnaire, Bangladesh

\section{Introduction}

Autism Spectrum Disorder (ASD) stands for a group of neurodevelopmental disorders that usually manifest deficits across three major behavioral components, namely (i) social interactions and communicative skills, (ii) restricted interest spectrum (eg, rigid routines or rituals, specific food and clothing preferences, and difficulty coping with the environment), and (iii) stereotyped and repetitive behaviors (eg, repetitive movement with object, recitative body movements such as rocking and hand-flapping). ${ }^{1-4}$ The social activities of children with ASDs (ASD) are restricted, although some ASD children are arguably able to lead independent and fulfilling lives. In general, life-long care and a supportive environment are needed for the majority of $\mathrm{ASD}$, due to frequently occurring educational 
achievements, difficulties in social interactions, as well as limited employment opportunities.

However, ASD are prone to suffering from a wideranging array of life-long difficulties, and the presence of sleep problems is one that is commonly reported as being much more prevalent than in typically developing children (TDC). ${ }^{5}$ For instance, the prevalence of sleep problems among ASD families is reported between $66 \%$ and $86 \%$, whereas $13 \%$ to $86 \%$ will suffer from sleep issues among children with other neurodevelopmental disorders, and $9 \%$ to $50 \%$ in TDC..$^{6-8}$ In the context of the sleep problems experienced among ASD, difficulty in falling asleep is the most frequent, whereas other prominent problems include(i) restless sleep, (ii) do not want to stay on own bed, (iii) sleep awakenings, iv) difficulty to wake up in the morning, v) reduced REM (Rapid Eye Movement) sleep and enhanced undifferentiated sleep, immature organization of eye movements into discrete bursts, less time in bed, reduced total sleep time, altered REM sleep latency. ${ }^{1,9}$ In contrast, common sleep problems among TDC included sleep walking, bed time resistance, nighttime awakenings and sleep terrors. ${ }^{10}$ Insufficient sleep or problems in the context of sleep behaviors increase the severity of autism symptoms, and generate an added level of stress and disruption in the family, ${ }^{1,11}$ further buttressing the importance of sleep in the context of ASD. ASD sleep problems are also associated with different adverse health outcomes, such as lower ability of motor coordination or verbal communication, reduced social interactions, higher anxiety, hyperactivity, aggression, and altered eating habits, to name a few. ${ }^{12}$

According to the World Health Organization report, one in 160 children $(0.625 \%)$ will be diagnosed with ASDs. ${ }^{13}$ In Bangladesh, the prevalence of ASD is estimated at $0.15 \%$ to $0.8 \%,{ }^{14}$ and may reach $3 \%$ in metropolitan areas, likely because of increased diagnostic access. However, arguably Bangladesh is experiencing a higher prevalence of children with ASDs, and studies assessing ASD common clinical issues such as sleep problems, are extremely scarce; among the currently available evidence, Begum et $\mathrm{al}^{15}$ reported on the distribution of socio-demographic characteristics, whereas another qualitative study by Preity et $\mathrm{al}^{16}$ studied ASD parental views towards autism. However, such limited information and reduced awareness as to the actual prevalence and clinical phenotypic manifestation of ASD in Bangladesh may arguably hinder the implementation of appropriate policies regarding the diagnosis and treatment of children with
ASD. Thus, the present study was conducted to assess the hypothesis that sleep problems were more frequent in ASD families and to assess whether such sleep-related difficulties were associated with socio-demographic factors among ASD and TDC families.

\section{Methods}

\section{Study Site and Participants}

The present comparative study was conducted between May and August 2019 and included the mothers with ASD children (M-ASD) and mothers of typically developing children (M-TDC) residing in Dhaka, the capital of Bangladesh. Based on the randomization school assignment, M-ASD participants were recruited from eight specialized schools of ASD children, whereas the M-TDC participants were recruited from twelve regular schools. The only inclusion criterion for participating in the interview was being a mother of a child aged between 4 and 15 years. A total of 512 mothers were approached to participate the study, and of these 446 mothers agreed and provided their informed consent. Their children's mean age was $8.1 \pm 2.9$ years. In total, data from $151 \mathrm{M}$-ASD (mean age of children $8.5 \pm 2.7$ years) and 295 M-TDC (mean age of children $7.9 \pm 3.0$ years) were available for analyses.

\section{Data Collection}

Face-to-face structured interviews were conducted in the schools. The research team randomly approached school administrators in the city, and after being granted formal permission by the appropriate school authorities, the survey interviews were carried out. Each interview lasted approximately 35 minutes, and all interviews took place during school opening hours. A structured questionnaire was administered by the research team, and comprised questions concerning socio-demographic characteristics, and the Child Sleep Habit Questionnaire (CSHQ).

\section{Measures}

\section{Sociodemographic Factors}

Questions concerning socio-demographic variables included age, education (number of years studied at school/college), occupation, family type, monthly income, total number of children, birth order of the child among the siblings. Family income was categorized based on Mamun and friends' study as either upper class (families having an income of more than 30,000 Bangladeshi Taka 
[BDT] a year), middle class (families having between 15,000 and 30,000 BDT a year), or lower class (families having less than 15,000 BDT a year). ${ }^{17}$ Use of sleeping pills was also assessed in this study.

\section{Child Sleep Habit Questionnaire}

Sleep problems were assessed using the Child Sleep Health Questionnaire [CSHQ; 8)]. The CSHQ contains 33 items related to a number of key sleep domains such as - (i) bedtime resistance, (ii) sleep onset delay, (iii) sleep duration, (iv) anxiety, (v) night walking, (vi) parasomnias, (vii) sleep disordered breathing, and (viii) daytime sleepiness. Information was obtained from the mothers of the child on the basis of recollection related to the last 2-3 weeks. Items are rated on a 3-point scale, if the sleep behaviors occur $\geq 5$ days/week, ie, "usually", whereas 2 to 4 days and 0 to 1 day are denoted as "sometimes" and "never", respectively. The CSHQ has a possible score ranging from 31 to 93 points, and higher scores indicate more sleep problems. However, a score of 41 points is considered as the cutoff for the presence of problematic sleep. ${ }^{18,19}$ Parent's perception regarding their child's sleep was also recorded.

\section{Ethics}

The study procedures were conducted in accordance with the Declaration of Helsinki, 1975. First of all, the study protocol was reviewed at the CHINTA Research Bangladesh. Later on, a formal ethical approval was granted by the ethics committee at the Institute of Allergy and Clinical Immunology of Bangladesh (Ref No: IRBIACIB/ECE/07201915/299). All mothers were informed about the purpose of the study and their informed consent was obtained prior to participation in the survey interview. Confidentiality of data and privacy of the participants was strictly maintained, and participants were informed that they had the right to withdraw from the study at any time.

\section{Statistical Analysis}

Data analyses were completed by using SPSS version 22.0 (Chicago, IL). Descriptive statistics (ie, percentage and frequencies) as well as inferential statistics (ie, chisquare test, independent $t$-test, and ANOVA test) were performed to identify potential relationships of child sleep problems with the variables under investigation among the ASD and TDC groups. In Table 1, the distribution of the participants across the child group was compared using chi-square tests. Comparisons on CSHQ overall and subscales scores across ASD and TD children were evaluated based on independent t-tests. In Table 3, independent t-tests, and ANOVA tests were used to see the relationship of the studied variables with insomnia based on (i) total children, (ii TD children, and (ii) ASD children. The statistical significance level was set at $p<0.01$ with $95 \%$ confidence intervals for the test.

\section{Results}

From a total of 446 mothers who completed the structured interview, $33.9 \%(n=151)$ were M-ASD and $66.1 \%$ were M-TDC. Among ASD, the proportion of male children was high $(n=121 / 151)$, whereas equal distribution of the two sexes occurred in TDC $(\mathrm{n}=51.5 \%)$. Half of the children were 4-7 years of age, $82.7 \%$ were from nuclear family, almost always from the higher socio-economic class (71.7\%), and mothers' and fathers' higher education levels were also ubiquitously present (Table 1). 21.9\% of the M-ASD reported a positive family history of ASD and $41.7 \%$ had no subsequent children after the birth of their ASD child. About $9.9 \%$ of all children were reported to be taking sleeping pills, primarily among ASD children (ie, $28.5 \%$ vs $0.3 \% ; \chi 2=88.928, p<0.001$ ) (Table 1 ).

Figure 1 presents the distribution of problematic sleep across the two groups. About $89.7 \%$ of the children were reported to have sleep problems, but the prevalence was higher in ASD compared to TDC $(94.00 \%$ vs $87.50 \% ; \chi^{2}=4.678, p=0.031$ ). Furthermore, the overall mean score in CSHQ was $48.67 \pm 7.56$ in the total sample, whereas ASD children reported higher scores compared to TDC ones $(50.90 \pm 8.11$ vs $47.53 \pm 7.01, p<0.001)$. Similarly, subscales of CSHQ such as sleep duration $(4.23 \pm 1.56$ vs $3.90 \pm 1.31, p=0.017)$, sleep anxiety ( 7.23 \pm 2.05 vs $6.45 \pm 1.92, p<0.001)$, night awakenings (3.82 \pm 1.07 vs $3.17 \pm 1.89, p<0.001)$, parasomnias $(8.86 \pm 2.06$ vs $7.85 \pm 2.27, \mathrm{~F}=20.589, p<0.001)$, and sleep disordered breathing $(4.02 \pm 2.92$ vs $3.43 \pm 2.07, p=0.014)$ were more prevalent among ASD compared to TDC. There were no significant differences between the two groups for the bedtime resistance, sleep onset delay, and daytime sleeping sub-items of the CSHQ (Table 2).

Table 3 represents the relationships within CSHQ overall scores and other variables as explored in the total cohort, ASD, and TDC. Of the socio-demographic items, the use of sleeping pills was significantly associated with sleep problems. The TDC who reported using sleeping 
Table I Distribution of the Socio-Demographic Variables of ASDs and TD Children

\begin{tabular}{|c|c|c|c|c|c|c|}
\hline \multirow[t]{2}{*}{ Variables } & \multirow[t]{2}{*}{ Total (n; \%) } & \multicolumn{2}{|l|}{ Child Type } & \multicolumn{3}{|c|}{ Statistics } \\
\hline & & ASD (n; \%) & TDC (n; \%) & $\chi^{2}$ Test Value & $d f$ & $p$-value \\
\hline \multicolumn{7}{|l|}{ Child type } \\
\hline ASD & $15 \mathrm{I} ; 33.9 \%$ & & & & & \\
\hline TDC & $295 ; 66.1 \%$ & & & & & \\
\hline \multicolumn{7}{|l|}{ Child gender } \\
\hline Male & $264 ; 59.2 \%$ & $121 ; 80.1 \%$ & $143 ; 48.5 \%$ & 41.440 & 1 & $<0.001$ \\
\hline Female & $182 ; 40.8 \%$ & $30 ; 19.9 \%$ & $152 ; 51.5 \%$ & & & \\
\hline \multicolumn{7}{|l|}{ Age group } \\
\hline 4-7 years & $223 ; 50.0 \%$ & $66 ; 43.7 \%$ & $157 ; 53.2 \%$ & 5.652 & 2 & 0.059 \\
\hline $8-11$ years & $153 ; 34.3 \%$ & $63 ; 41.7 \%$ & $90 ; 30.5 \%$ & & & \\
\hline $12-15$ years & $70 ; 15.7 \%$ & $22 ; 14.6 \%$ & $48 ; 16.3 \%$ & & & \\
\hline \multicolumn{7}{|l|}{ Family type } \\
\hline Nuclear family & $369 ; 82.7 \%$ & $125 ; 82.8 \%$ & $244 ; 82.7 \%$ & 0.000 & 1 & 0.985 \\
\hline Joint family & $77 ; 17.3 \%$ & $26 ; 17.2 \%$ & $51 ; 17.3 \%$ & & & \\
\hline \multicolumn{7}{|c|}{ Monthly family income (BDT) } \\
\hline Less than 15,000 & $6 ; 1.3 \%$ & $2 ; 1.3 \%$ & $4 ; 1.4 \%$ & 14.162 & 2 & $<0.001$ \\
\hline 15,000 to 30,000 & $120 ; 26.9 \%$ & $24 ; 15.9 \%$ & $96 ; 32.5 \%$ & & & \\
\hline More than 30,000 & $320 ; 71.7 \%$ & $125 ; 82.8 \%$ & $195 ; 66.1 \%$ & & & \\
\hline \multicolumn{7}{|c|}{ Fathers' educational qualification } \\
\hline Less than grade 5 & $34 ; 7.6 \%$ & $6 ; 4.0 \%$ & $28 ; 9.5 \%$ & 15.693 & 2 & $<0.001$ \\
\hline Grade 5 to 10 & $38 ; 8.5 \%$ & $4 ; 2.6 \%$ & $34 ; 11.5 \%$ & & & \\
\hline Higher (grade $10+$ ) & $374 ; 83.9 \%$ & $|4| ; 93.4 .0 \%$ & $233 ; 79.0 \%$ & & & \\
\hline \multicolumn{7}{|c|}{ Mothers' educational qualification } \\
\hline Less than grade 5 & $38 ; 8.5 \%$ & $7 ; 4.6 \%$ & $31 ; 10.5 \%$ & 14.839 & 2 & $<0.001$ \\
\hline Grade 5 to 10 & $48 ; 10.8 \%$ & $7 ; 4.6 \%$ & $41 ; 13.9 \%$ & & & \\
\hline Higher (grade $10+$ ) & $360 ; 80.7 \%$ & I37; 90.7\% & $223 ; 75.6 \%$ & & & \\
\hline \multicolumn{7}{|l|}{ Fathers' profession } \\
\hline Service & $297 ; 67.0 \%$ & $95 ; 63.3 \%$ & $1202 ; 68.9 \%$ & 5.013 & 2 & 0.082 \\
\hline Business & $137 ; 30.9 \%$ & $49 ; 32.7 \%$ & $88 ; 30.0 \%$ & & & \\
\hline Others & $9 ; 2.0 \%$ & $6 ; 4.0 \%$ & $3 ; 1.0 \%$ & & & \\
\hline \multicolumn{7}{|l|}{ Mothers' profession } \\
\hline Housewife & $375 ; 84.5 \%$ & $130 ; 86.1 \%$ & $245 ; 83.6 \%$ & 4.906 & 2 & 0.086 \\
\hline Service & $67 ; 15.1 \%$ & $19 ; 12.6 \%$ & $48 ; 16.4 \%$ & & & \\
\hline Others & $2 ; 0.5 \%$ & $2 ; 1.3 \%$ & & & & \\
\hline \multicolumn{7}{|l|}{ Total child } \\
\hline One & $142 ; 31.8 \%$ & $42 ; 27.8 \%$ & $100 ; 33.9 \%$ & 1.703 & 1 & 0.192 \\
\hline More than one & $304 ; 68.2 \%$ & $109 ; 72.2 \%$ & $195 ; 66.1 \%$ & & & \\
\hline
\end{tabular}

(Continued) 
Table I (Continued).

\begin{tabular}{|c|c|c|c|c|c|c|}
\hline \multirow[t]{2}{*}{ Variables } & \multirow[t]{2}{*}{ Total (n; \%) } & \multicolumn{2}{|l|}{ Child Type } & \multicolumn{3}{|c|}{ Statistics } \\
\hline & & $\operatorname{ASD}(\mathrm{n} ; \%)$ & TDC ( $n ; \%)$ & $\chi^{2}$ Test Value & $d f$ & $p$-value \\
\hline \multicolumn{7}{|c|}{ Birth order of the child } \\
\hline First & $266 ; 59.6 \%$ & $101 ; 66.9 \%$ & $165 ; 55.9 \%$ & 7.085 & 2 & 0.029 \\
\hline Second & $143 ; 32.1 \%$ & $36 ; 23.8 \%$ & $107 ; 36.3 \%$ & & & \\
\hline Third & $37 ; 8.3 \%$ & $14 ; 9.3 \%$ & $23 ; 7.8 \%$ & & & \\
\hline \multicolumn{7}{|c|}{ Had any child after ASD born } \\
\hline Yes & $63 ; 41.7 \%$ & $63 ; 41.7 \%$ & & & & \\
\hline No & $88 ; 58.3 \%$ & $88 ; 58.3 \%$ & & & & \\
\hline \multicolumn{7}{|c|}{ Family history of ASD } \\
\hline Yes & $33 ; 21.9 \%$ & $33 ; 21.9 \%$ & & & & \\
\hline No & II8; $78.1 \%$ & $118 ; 78.1 \%$ & & & & \\
\hline \multicolumn{7}{|c|}{ Use of sleeping pills } \\
\hline Yes & $44 ; 9.9 \%$ & $43 ; 28.5 \%$ & $\mathrm{I} ; 0.3 \%$ & 88.928 & I & $<0.001$ \\
\hline No & $402 ; 90.1 \%$ & 108; 71.5\% & 294; 99.7\% & & & \\
\hline
\end{tabular}

pills scored higher on the CSHQ scale when compared to $\operatorname{ASD}(66.00 \pm 0.00$ vs $53.30 \pm 9.69)$.

\section{Discussion}

Sufficient and adequate sleep is vital for maintaining cognitive and emotional development. Conversely, the presence of sleep disturbances is associated with serious physical and mental health consequences, further leading to deterioration of quality of life. ${ }^{20-23}$ Such issues are particularly prominent among children suffering from developmental disorders. Although previous studies in developed countries have now conclusively shown that children with ASD are more vulnerable to sleep problems, studies in Bangladeshi children have never been pursued. Thus, the present study provides important information on this regarding the context of an LMIC where the awareness and diagnosis of ASD is still lagging.

Using the CHSQ score of 41 as the cutoff point, ${ }^{18,19}$ we found that ASD children are more likely than TDC to present with sleep problems and their overall scores are also higher. It is possible that the perception of children's quality sleep in Bangladesh may differ from other countries, possibly because parents and children are more likely to sleep in the same room, or because parents are more likely to watch their children during their sleep as opposed to parental habits in developed economies. ${ }^{24,25}$ Higher prevalence of sleep problems has been reported among
ASD (66\% to $86 \%$ ), when compared to either children with other neurodevelopmental disorders (13\% to $86 \%$ ) or TDC (9\% to $50 \%){ }^{6-8}$ The CHSQ scores reported here are relatively higher than those reported in India, the neighboring country of Bangladesh (ie, 48.1 [ \pm 7.6$]$ vs $41.4[ \pm 4.2] ; p=0.001){ }^{26}$ However, utilizing the same instrument, the present mean score of ASD was also higher than the CHSQ scores reported in China [47.69 $\left.\pm 9.28^{27}\right]$, America $\left[47.39 \pm 8.21^{27}, 48.83 \pm 9.68^{28}, 49.06\right.$ $\left.\pm 8.95^{19}\right]$, Canada $\left[42.09 \pm 3.53^{29}\right]$, and Israel $[50.74$ $\left.\pm 1.13^{30}\right]$. However, in a study of ASD children in Oman, a similar or slightly higher CHSQ score emerged in ASD children [ie, 51.1 $\pm 7.8^{31}$ ]. Interestingly, the frequency of use of pharmacological sleeping aids may serve as a better and more robust indicator of sleep problems in ASD. $^{32-35}$ In this context, $28.5 \%$ of the present ASD reported using sleeping pills, as opposed to only $0.3 \%$ of TDC.

The CHSQ collates a large variety of sleep problems and even when analyzing the various subsets separately, Bangladeshi ASD children consistently reported higher scores when compared to TDC in the majority of the subitems. $^{36-39}$ Some of these sleep issues are potentially disruptive to family stability and can impose substantial stress that further compounds the perception of altered sleep. For example, parasomnias that co-occur in the setting of underlying bedtime resistance can add substantial 


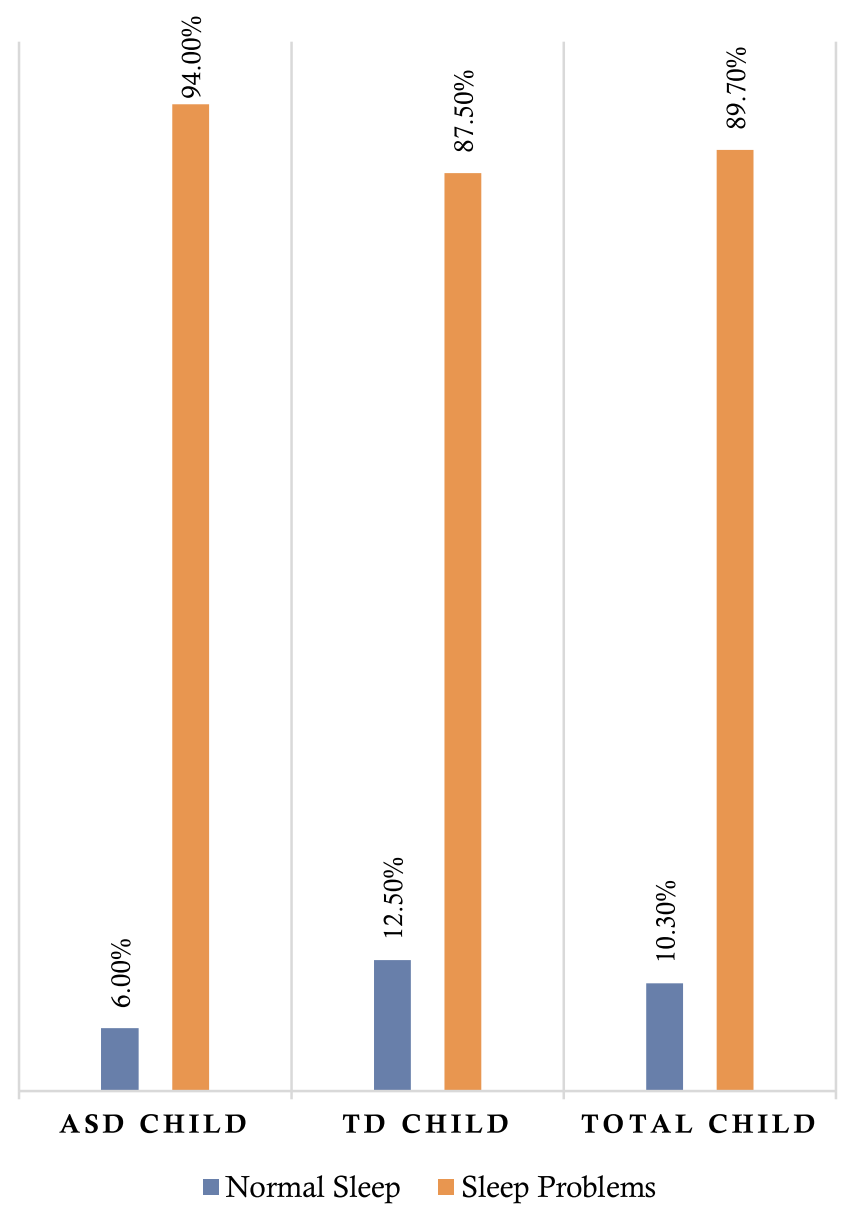

Figure I Distribution of problematic sleep across ASD and TDC children.

distress to families. ${ }^{28,37}$ Similarly, the presence of sleepdisordered breathing may further exacerbate ASD children's stereotyped behaviors, social interaction problems and lead to increased assessments of overall level of ASD severity. ${ }^{40}$ Conversely, improvements in sleep may lead to improvement in social communication, attention, and reductions in the frequency of repetitive behaviors in patients with ASD.
Some studies have reported that girls with ASD may exhibit reduced sleep duration ${ }^{41,42}$; however, this is not consistent with our present findings. Other demographic factors (for example, parental education levels) seemed to be unrelated to the presence of sleep problems in our cohort. It is possible, albeit still uncertain, that higher education may enable more intense levels of clinical care among ASD children and that such interventions may palliate and mitigate the frequency and severity of sleep problems in their children. As alluded above, children belonging to lower income families may be more likely to share bedrooms, have a television in the bedroom, ${ }^{43}$ and live in a "noisy home environment", ${ }^{44}$ all of which can foster or enhance poor sleep. Indeed, Bagley et $\mathrm{al}^{45}$ suggested that sleeping environments are responsible for disruptive sleeping behaviors. Notwithstanding, we found no associations between socio-economic status and sleep disturbances, and previous studies in other countries did not examine this particular issue, such that comparisons are precluded. $^{41,46}$

A few methodological limitations merit mention in relation to the present study. For example, information was based on subjective parental reports. Accordingly, use of more objective assessments of sleep as well as indepth evaluation of ASD severity would be highly desirable. ${ }^{31}$ Indeed, assessment of potential associations between ASD severity as well as the presence of other co-morbidities and the magnitude of CHSQ scores was not possible. Despite the aforementioned limitations, the present study provides initial observations on sleep problems in children with ASD in Bangladesh, which may help facilitate further studies, and lead to recommendations for changes in current (primary health care service to detect ASD) healthcare policies. For example, development and implementation of educational programs for

Table 2 Comparison on CSHQ Overall and Subscales Scores Across ASD and TD Children

\begin{tabular}{|c|c|c|c|c|c|}
\hline \multirow[t]{2}{*}{ Variables (Mean \pm SD) } & \multirow[t]{2}{*}{ Total Child } & \multicolumn{4}{|c|}{ Mean and SD Score Across Child Type } \\
\hline & & ASD Child & TD Child & T value & $p$-value \\
\hline CSHQ overall & $48.67 \pm 7.56$ & $50.90 \pm 8.11$ & $47.53 \pm 7.01$ & 20.669 & $<0.001$ \\
\hline Bedtime resistance & $11.70 \pm 2.76$ & $11.79 \pm 2.69$ & $11.66 \pm 2.80$ & 0.223 & 0.630 \\
\hline Sleep onset delay & $1.74 \pm 0.89$ & $1.76 \pm 0.88$ & $1.73 \pm 0.90$ & 0.132 & 0.716 \\
\hline Sleep duration & $4.01 \pm 1.41$ & $4.23 \pm 1.56$ & $3.90 \pm 1.31$ & 5.742 & 0.017 \\
\hline Sleep anxiety & $6.71 \pm 2.00$ & $7.23 \pm 2.05$ & $6.45 \pm 1.92$ & 15.515 & $<0.001$ \\
\hline Night waking & $3.39 \pm 1.69$ & $3.82 \pm 1.07$ & $3.17 \pm 1.89$ & 15.158 & $<0.001$ \\
\hline Parasomnias & $8.19 \pm 2.25$ & $8.86 \pm 2.06$ & $7.85 \pm 2.27$ & 20.589 & $<0.001$ \\
\hline Sleep disordered breathing & $3.63 \pm 2.40$ & $4.02 \pm 2.92$ & $3.43 \pm 2.07$ & 6.111 & 0.014 \\
\hline Daytime sleepiness & $13.17 \pm 3.86$ & $13.24 \pm 4.43$ & $13.14 \pm 3.53$ & 0.066 & 0.798 \\
\hline
\end{tabular}


Table 3 Comparison of CSHQ Scores and Socio-Demographic Variables Between ASD and TD Children

\begin{tabular}{|c|c|c|c|c|c|c|}
\hline \multirow[t]{2}{*}{ Variables } & \multicolumn{2}{|l|}{ Total Child } & \multicolumn{2}{|l|}{ ASD Child } & \multicolumn{2}{|l|}{ TD Child } \\
\hline & Mean \pm SD & $p$-value & Mean \pm SD & $p$-value & Mean \pm SD & $p$-value \\
\hline \multicolumn{7}{|l|}{ Child gender } \\
\hline $\begin{array}{l}\text { Male } \\
\text { Female }\end{array}$ & $\begin{array}{l}48.73 \pm 7.48 \\
48.60 \pm 7.69\end{array}$ & 0.862 & $\begin{array}{l}50.42 \pm 7.99 \\
52.83 \pm 8.42\end{array}$ & 0.147 & $\begin{array}{l}47.29 \pm 6.72 \\
47.76 \pm 7.28\end{array}$ & 0.561 \\
\hline \multicolumn{7}{|l|}{ Age group } \\
\hline $\begin{array}{l}4-7 \text { years } \\
8-11 \text { years } \\
12-15 \text { years }\end{array}$ & $\begin{array}{l}49.07 \pm 6.78 \\
48.99 \pm 7.57 \\
46.74 \pm 9.49\end{array}$ & 0.065 & $\begin{array}{l}50.81 \pm 7.65 \\
51.63 \pm 8.32 \\
49.09 \pm 8.89\end{array}$ & 0.449 & $\begin{array}{l}48.33 \pm 6.25 \\
47.14 \pm 6.43 \\
45.66 \pm 9.66\end{array}$ & 0.056 \\
\hline \multicolumn{7}{|l|}{ Family type } \\
\hline $\begin{array}{l}\text { Nuclear family } \\
\text { Joint family }\end{array}$ & $\begin{array}{l}48.60 \pm 7.50 \\
49.02 \pm 7.88\end{array}$ & 0.659 & $\begin{array}{l}50.95 \pm 8.55 \\
50.69 \pm 5.69\end{array}$ & 0.883 & $\begin{array}{l}47.40 \pm 6.61 \\
48.17 \pm 872\end{array}$ & 0.476 \\
\hline \multicolumn{7}{|c|}{ Monthly family income (BDT) } \\
\hline $\begin{array}{l}\text { Less than } 15,000 \\
15,000 \text { to } 30,000 \\
\text { More than } 30,000\end{array}$ & $\begin{array}{l}48.00 \pm 4.81 \\
47.26 \pm 6.54 \\
49.22 \pm 7.90\end{array}$ & 0.053 & $\begin{array}{l}48.50 \pm 3.53 \\
48.66 \pm 7.71 \\
51.37 \pm 8.20\end{array}$ & 0.300 & $\begin{array}{l}47.75 \pm 5.85 \\
46.91 \pm 6.21 \\
47.84 \pm 7.40\end{array}$ & 0.573 \\
\hline \multicolumn{7}{|c|}{ Fathers' educational qualification } \\
\hline $\begin{array}{l}\text { Less than grade } 5 \\
\text { Grade } 5 \text { to } 10 \\
\text { Higher }\end{array}$ & $\begin{array}{l}48.70 \pm 7.29 \\
48.23 \pm 8.83 \\
48.72 \pm 7.47\end{array}$ & 0.932 & $\begin{array}{l}54.50 \pm 10.25 \\
49.25 \pm 8.46 \\
50.80 \pm 8.03\end{array}$ & 0.508 & $\begin{array}{l}47.46 \pm 6.03 \\
48.11 \pm 8.98 \\
47.46 \pm 6.82\end{array}$ & 0.878 \\
\hline \multicolumn{7}{|c|}{ Mothers' educational qualification } \\
\hline $\begin{array}{l}\text { Less than grade } 5 \\
\text { Grade } 5 \text { to } 10 \\
\text { Higher }\end{array}$ & $\begin{array}{l}48.55 \pm 7.39 \\
48.16 \pm 8.88 \\
48.76 \pm 7.41\end{array}$ & 0.873 & $\begin{array}{l}51.42 \pm 6.16 \\
53.57 \pm 9.51 \\
50.74 \pm 8.15\end{array}$ & 0.660 & $\begin{array}{l}47.90 \pm 7.58 \\
47.24 \pm 8.55 \\
47.54 \pm 6.64\end{array}$ & 0.925 \\
\hline \multicolumn{7}{|l|}{ Fathers' profession } \\
\hline $\begin{array}{l}\text { Service } \\
\text { Business } \\
\text { Others }\end{array}$ & $\begin{array}{l}48.39 \pm 7.28 \\
49.04 \pm 7.93 \\
51.77 \pm 10.46\end{array}$ & 0.327 & $\begin{array}{l}50.48 \pm 8.25 \\
51.34 \pm 7.35 \\
55.83 \pm 10.75\end{array}$ & 0.272 & $\begin{array}{l}47.41 \pm 6.57 \\
47.76 \pm 7.99 \\
43.66 \pm 0.57\end{array}$ & 0.593 \\
\hline \multicolumn{7}{|l|}{ Mothers' profession } \\
\hline $\begin{array}{l}\text { Housewife } \\
\text { Service } \\
\text { Others }\end{array}$ & $\begin{array}{l}48.81 \pm 7.53 \\
48.04 \pm 7.88 \\
47.50 \pm 4.94\end{array}$ & 0.727 & $\begin{array}{l}50.96 \pm 8.17 \\
50.89 \pm 8.19 \\
47.50 \pm 4.94\end{array}$ & 0.838 & $\begin{array}{l}47.67 \pm 6.92 \\
46.91 \pm 7.55 \\
-\end{array}$ & 0.494 \\
\hline \multicolumn{7}{|l|}{ Total child } \\
\hline $\begin{array}{l}\text { One } \\
\text { More than one }\end{array}$ & $\begin{array}{l}48.95 \pm 7.43 \\
48.54 \pm 7.63\end{array}$ & 0.596 & $\begin{array}{l}49.69 \pm 7.83 \\
51.37 \pm 8.20\end{array}$ & 0.254 & $\begin{array}{l}48.65 \pm 7.27 \\
46.96 \pm 6.82\end{array}$ & 0.051 \\
\hline \multicolumn{7}{|l|}{ Birth order of the child } \\
\hline $\begin{array}{l}\text { First } \\
\text { Second } \\
\text { Third }\end{array}$ & $\begin{array}{l}48.82 \pm 7.70 \\
48.21 \pm 7.28 \\
49.43 \pm 7.69\end{array}$ & 0.608 & $\begin{array}{l}50.75 \pm 8.53 \\
50.91 \pm 7.32 \\
52.00 \pm 7.34\end{array}$ & 0.866 & $\begin{array}{l}47.64 \pm 6.92 \\
47.30 \pm 7.08 \\
47.86 \pm 7.62\end{array}$ & 0.904 \\
\hline
\end{tabular}


Table 3 (Continued).

\begin{tabular}{|c|c|c|c|c|c|c|}
\hline \multirow[t]{2}{*}{ Variables } & \multicolumn{2}{|l|}{ Total Child } & \multicolumn{2}{|l|}{ ASD Child } & \multicolumn{2}{|l|}{ TD Child } \\
\hline & Mean \pm SD & $p$-value & Mean \pm SD & $p$-value & Mean \pm SD & $p$-value \\
\hline \multicolumn{7}{|c|}{ Had any child after ASD child } \\
\hline $\begin{array}{l}\text { Yes } \\
\text { No }\end{array}$ & $\begin{array}{l}51.50 \pm 8.65 \\
50.47 \pm 7.72\end{array}$ & 0.443 & $\begin{array}{l}51.50 \pm 8.65 \\
50.47 \pm 7.72\end{array}$ & 0.443 & & - \\
\hline \multicolumn{7}{|c|}{ Family history of autism } \\
\hline $\begin{array}{l}\text { Yes } \\
\text { No }\end{array}$ & $\begin{array}{l}52.75 \pm 8.28 \\
50.38 \pm 8.02\end{array}$ & 0.139 & $\begin{array}{l}52.75 \pm 8.28 \\
50.38 \pm 8.02\end{array}$ & 0.1399 & & - \\
\hline \multicolumn{7}{|c|}{ Use of sleeping pill } \\
\hline $\begin{array}{l}\text { Yes } \\
\text { No }\end{array}$ & $\begin{array}{l}53.59 \pm 9.77 \\
48.14 \pm 7.09\end{array}$ & $<0.001$ & $\begin{array}{l}53.30 \pm 9.69 \\
49.95 \pm 7.22\end{array}$ & 0.022 & $\begin{array}{l}66.00 \pm 0.00 \\
47.47 \pm 6.94\end{array}$ & 0.008 \\
\hline
\end{tabular}

ASD parents regarding lifestyle changes for their child (eg, bedtime routines) at the community level to alleviate sleep disturbances among ASD children and mitigate the impact of such disturbances on the whole household.

\section{Conclusions}

In summary, Bangladeshi children in general and those with ASD appear to be more likely to report sleep disturbances. Thus, early screening and diagnosis of such sleep problems and their potential underpinnings may enable interventions aimed at mitigating the adverse consequences of sleep disorders while contributing to increase the quality of life of the children and their families.

\section{Acknowledgments}

The authors are thankful to all the participants and team members involved in the project implementation (especially Sharmin Jahan). Besides, the authors also like to acknowledge that the project was run by Undergraduate Research Organization, currently which will be introduced as CHINTA Research Bangladesh (Centre for Health Innovation, Networking, Training, Action and Research Bangladesh).

\section{Funding}

Dr. Qian Yu acknowledges the funding support received as: Overseas High-Caliber Personnel Fund (Level C: 20191105534C).

\section{Disclosure}

The authors of the research work do not have any conflict of interest.

\section{References}

1. Cortesi F, Giannotti F, Ivanenko A, Johnson K. Sleep in children with autistic spectrum disorder. Sleep Med. 2010;11(7):659-664. doi:10.1016/j.sleep.2010.01.010

2. Leekam SR, Prior MR, Uljarevic M. Restricted and repetitive behaviors in autism spectrum disorders: a review of research in the last decade. Psychol Bull. 2011;137:562.

3. Frye RE. Social skills deficits in autism spectrum disorder: potential biological origins and progress in developing therapeutic agents. CNS Drugs. 2018;32:713-734.

4. American Psychiatric Association. Diagnostic and Statistical Manual of Mental Disorders $\left(D S M-5^{\circledR}\right)$. 5th ed. Arlington, VA: American Psychiatric Publishing;2013.

5. Devnani PA, Hegde AU. Autism and sleep disorders. J Pediatr Neurosci. 2015;10:304-307.

6. Elrod MG, Hood BS. Sleep differences among children with autism spectrum disorders and typically developing peers: a meta-analysis. J Dev Behav Pediatr. 2015;36:166-177.

7. Knight RM, Johnson CM. Using a behavioral treatment package for sleep problems in children with autism spectrum disorders. Child Fam Behav Ther. 2014;36:204-221.

8. Richdale AL, Schreck KA. Sleep problems in autism spectrum disorders: prevalence, nature, \& possible biopsychosocial aetiologies. Sleep Med Rev. 2009;13:403-411.

9. Gail Williams P, Sears LL, Allard A. Sleep problems in children with autism. J Sleep Res. 2004;13:265-268.

10. Goodlin-Jones B, Schwichtenberg AJ, Iosif A-M, Tang K, Liu J, Anders TF. Six-month persistence of sleep problems in young children with autism, developmental delay, and typical development. J Am Acad Child Adolesc Psychiatry. 2009;48:847-854.

11. Malow BA, Marzec ML, McGrew SG, Wang L, Henderson LM, Stone WL. Characterizing sleep in children with autism spectrum disorders: a multidimensional approach. Sleep. 2006;29:1563-1571.

12. Goldman SE, McGrew S, Johnson KP, Richdale AL, Clemons T, Malow BA. Sleep is associated with problem behaviors in children and adolescents with autism spectrum disorders. Res Autism Spectr Disord. 2011;5:1223-1229. 
13. WHO. Autism Spectrum Disorders. (2018) Available from: https:// www.who.int/news-room/fact-sheets/detail/autism-spectrumdisorders.

14. Hossain MD, Ahmed HU, Uddin MMJ, et al. Autism Spectrum disorders (ASD) in South Asia: a systematic review. BMC Psychiatry. 2017;17:281.

15. Begum FA, Rahman ASMMH, Islam MS. Socio-demographic status of children with autism spectrum disorder and their parents in Dhaka city. Int J Hum Heal Sci. 2019;4:36-40.

16. Preity S, Delwer M, Hawlader H, Akhter S, Abdullah AS, Biswas A Views of the parents of Autistic children about Autism and schools for Autistic children: a qualitative study in urban Bangladesh. Int J Public Heal Res. 2017;5:56-61.

17. Mamun MA, Misti JM, Hosen I, Al mamun F. Suicidal behaviors and university entrance test-related factors: a Bangladeshi exploratory study. Perspect Psychiatr Care. 2021;1-10.

18. Owens JA, Spirito A, McGuinn M. The Children's Sleep Habits Questionnaire (CSHQ): psychometric properties of a survey instrument for school-aged children. Sleep. 2000;23:1043-1052.

19. Johnson CR, Turner KS, Foldes EL, Malow BA, Wiggs L. Comparison of sleep questionnaires in the assessment of sleep disturbances in children with autism spectrum disorders. Sleep Med. 2012;13:795-801.

20. Chattu V, Manzar MD, Kumary S, Burman D, Spence D, PandiPerumal S. The global problem of insufficient sleep and its serious public health implications. Healthcare. 2019;7:1.

21. Mamun MA, Hossain MS, Kamruzzaman M, et al. Prevalence of poor sleep quality and its determinants among Bangladeshi students: a pilot study. Sleep Vigil. 2020;4:185-193.

22. Manzar MD, Salahuddin M, Maru TT, et al. Sleep correlates of substance use in community-dwelling Ethiopian adults. Sleep Breath. 2017;21:1005-1011.

23. Ghrouz AK, Noohu MM, Manzar MD, Spence DW, BaHammam AS, Pandi-Perumal SR. Physical activity and sleep quality in relation to mental health among college students. Sleep Breath. 2019;23:627-634.

24. Bharti B, Malhi P, Kashyap S. Patterns and problems of sleep in school going children. Indian Pediatr. 2006;43:35-38.

25. Montgomery-Downs HE, Gozal D. Sleep habits and risk factors for sleep-disordered breathing in infants and young toddlers in Louisville, Kentucky. Sleep Med. 2006;7:211-219.

26. Aathira R, Gulati S, Tripathi M, et al. Prevalence of sleep abnormalities in Indian children with autism spectrum disorder: a cross-sectional study. Pediatr Neurol. 2017;74:62-67.

27. Wang G, Liu Z, Xu G, et al. Sleep disturbances and associated factors in Chinese children with autism spectrum disorder: a retrospective and cross-sectional study. Child Psychiatry Hum Dev. 2016;47:248-258.

28. Hodge D, Carollo TM, Lewin M, Hoffman CD, Sweeney DP. Sleep patterns in children with and without autism spectrum disorders: developmental comparisons. Res Dev Disabil. 2014;35:1631-1638.

29. Lambert A, Tessier S, Rochette A-C, Scherzer P, Mottron L, Godbout R. Poor sleep affects daytime functioning in typically developing and autistic children not complaining of sleep problems: a questionnaire-based and polysomnographic study. Res Autism Spectr Disord. 2016;23:94-106.

30. Tzischinsky O, Meiri G, Manelis L, et al. Sleep disturbances are associated with specific sensory sensitivities in children with autism. Mol Autism. 2018;9:22.
31. Al-Farsi OA, Al-Farsi YM, Al-Sharbati MM, Al-Adawi S. Sleep habits and sleep disorders among children with autism spectrum disorders, intellectual disabilities and typically developing children in Oman: a case-control study. Early Child Dev Care. 2019;189:2370-2380.

32. Miano S, Ferri R. Epidemiology and management of insomnia in children with autistic spectrum disorders. Pediatr Drugs. 2010;12:75-84.

33. Malow B, Adkins KW, McGrew SG, et al. Melatonin for sleep in children with autism: a controlled trial examining dose, tolerability, and outcomes. J Autism Dev Disord. 2012;42:1729-1737.

34. Rzepka-Migut B, Paprocka J. Efficacy and safety of melatonin treatment in children with Autism Spectrum Disorder and AttentionDeficit/Hyperactivity Disorder - a review of the literature. Brain Sci. 2020;10:219.

35. Buckley AW, Sassower K, Rodriguez AJ, et al. An open label trial of donepezil for enhancement of rapid eye movement sleep in young children with autism spectrum disorders. $J$ Child Adolesc Psychopharmacol. 2011;21:353-357.

36. Esbensen AJ, Schwichtenberg AJ. Sleep in neurodevelopmental disorders. Int Rev Res Dev Disabil. 2016;51:153-191.

37. Giannotti F, Cortesi F, Cerquiglini A, et al. An investigation of sleep characteristics, EEG abnormalities and epilepsy in developmentally regressed and non-regressed children with autism. J Autism Dev Disord. 2008;38:1888-1897.

38. Ming X, Sun Y-M, Nachajon RV, Brimacombe M, Walters AS. Prevalence of parasomnia in autistic children with sleep disorders. Clin Med Pediatr. 2009;3:CMPed-S1139.

39. Tsai F-J, Chiang H-L, Lee C-M, et al. Sleep problems in children with autism, attention-deficit hyperactivity disorder, and epilepsy. Res Autism Spectr Disord. 2012;6:413-421.

40. Hoffman CD, Sweeney DP, Gilliam JE, Lopez-Wagner MC. Sleep problems in children with autism and in typically developing children. Focus Autism Other Dev Disabl. 2006;21:146-152.

41. Hollway JA, Aman MG, Butter E. Correlates and risk markers for sleep disturbance in participants of the autism treatment network. J Autism Dev Disord. 2013;43:2830-2843.

42. Kang Y-Q, Song X-R, Wang G-F, Su -Y-Y, Li P-Y, Zhang X. Sleep problems influence emotional/behavioral symptoms and repetitive behavior in preschool-aged children with Autism Spectrum Disorder in the unique social context of China. Front Psychiatry. 2020;11:273.

43. Milan S, Snow S, Belay S. The context of preschool children's sleep: racial/ethnic differences in sleep locations, routines, and concerns. J Fam Psychol. 2007;21:20.

44. Zhang J, Li AM, Kong APS, Lai KYC, Tang NLS, Wing YK. A community-based study of insomnia in Hong Kong Chinese children: prevalence, risk factors and familial aggregation. Sleep Med. 2009;10:1040-1046.

45. Bagley EJ, Kelly RJ, Buckhalt JA, El-Sheikh M. What keeps low-SES children from sleeping well: the role of presleep worries and sleep environment. Sleep Med. 2015;16:496-502.

46. Mayes SD, Calhoun SL. Variables related to sleep problems in children with Autism. Res Autism Spectr Disord. 2009;3:931-941. 


\section{Publish your work in this journal}

Nature and Science of Sleep is an international, peer-reviewed, open access journal covering all aspects of sleep science and sleep medicine, including the neurophysiology and functions of sleep, the genetics of sleep, sleep and society, biological rhythms, dreaming, sleep disorders and therapy, and strategies to optimize healthy sleep.
The manuscript management system is completely online and includes a very quick and fair peer-review system, which is all easy to use. Visit http://www.dovepress.com/testimonials.php to read real quotes from published authors. 